\title{
The Training of General Practitioner in China
}

\author{
Na Wang \\ Department of Anesthesiology \\ The First Hospital of Jilin University \\ Changchun, China \\ wangna080613@163.com
}

\author{
Corresponding author: Jinguo Wang* \\ Department of Urology \\ The First Hospital of Jilin University \\ Changchun, China \\ wangjinguolily@163.com
}

\begin{abstract}
The objective is to explore implementation plan of the training of general practitioner to meet the needs of health service development in our country. The focus of the plan is to improve the ability of resident in general medicine. On the base of literature research, we analyze the status of the general practitioner training in China and at abroad. According to the basic principle and the characteristics of general practitioners, we put forward work demands and the core competence of the general practitioners in China.
\end{abstract}

Keywords—-training; general practitioner; health service; work requirement; assessment

\section{INTRODUCTION}

Clinical medicine in the 21st century education based on post competence oriented systems engineering, and doctor students must integrate with the view of the development of things, medical defect is an impediment to the development of the education transformation. This article from training with the perspective of post competence of medical students, expounds the importance of job training in general medicine, there may be a problem [1].

\section{The TRAINING OF GENERAL PRACTITIONERS}

Job training in general medicine refers to engage in or near clinical practitioners working in the field of community health service transition training in general medicine, received general medical education in China is the largest number of education mode, it is determined by Chinese national conditions. In order to ensure the quality of training doctors in line with the general practitioner, according to the specific situation of the students according to their aptitude, is worthy of our concern [2]. General medicine education goal and the teaching content set should be guided by the demands of community health service, strengthen the interdisciplinary knowledge closely related to general medicine, such as social medicine, behavioral medicine, epidemiology and so on, so that the students in the process of training the sort of knowledge structure in general medicine, general medical knowledge system to consummate gradually.

Medical research is not only to provide scientific theory for the human health and disease prevention and control, must provide can be applied for clinical practical and effective new technology and new methods. At the beginning of the 20th century, for the sake of the development of science, basic medicine and clinical medicine of differentiation into, but differentiation must not be out of the "people-oriented" and "patient-centered" development direction and research goal.
Medicine and the trend of internationalization of medical education are becoming ever more obvious.

However, throughout our country current medical education system has low cost of education, personnel training cycle is short, the defects of our country medical education development obstacles caused by increasingly highlighted. Embodied in clinical medical students lack of real clinical practice skills, and the foundation of scientific research achievement of medical students clinical value is very weak. In our country, most of the medical colleges' stage, basic education and clinical education stage separation are very serious. It is one of the main clinical medical students, master's lack of real clinical practice skills, and the foundation of scientific research achievement of medical students, graduate students many stages of only stay on paper.

\section{THE IMPROVEMENT OF TEACHERS’ ABILITY FOR THE TRAINING OF GENERAL PRACTITIONERS}

At abroad, it has clear requirements for teachers in general medicine and admittance system, such as Australia must meet requirements of teachers in general medicine six basic conditions, including medical ethics, morality, professionalism, desire and action to provide training and time for training. And although our country, some experts of theory in general medicine faculty recommendations to degree level, work experience and the title, but not strictly in accordance with its execution. Out of the insufficiency, the current problem is not only a number of teachers, notably in structure and quality defects [3]. Teachers in general medicine to accept continuing medical education in China is not yet clear requirements, general medical national continuing medical projects are numbered, so many teachers in general medicine for continuing medical education has certain difficulty. Therefore, apprenticeship in Australia can cause our thinking Australian apprenticeship application in our country should further the research.

Medicine is a complete whole, which is separated according to the late former flatly, will inevitably lead to medical students learned about their medical knowledge lack of practical experience, which is difficult to form the ability to digest. In our country, medical students graduate work for medical practitioners examination qualified a year later, which will become the so-called legitimate doctor. However, at present a large number of medium and small hospitals at the grass-roots level actually not have training residency requirement. Medical students work in the hospital, in fact, it is difficult to by the system, standardize the basic vocational 
skills training, resulting in their medical practice is not standard. Over the years, tens of thousands of our basic medical research paper, but only a few can and have the results of transformation. Over the years, the clinical application of drugs, methods, technology, equipment, is emerge in endlessly, but from the hospital, the institute, the school is a handful. Medical science is the science of practical, to cultivate qualified medical talents. The key is to cultivate the student's ability of period [4]. Current medical colleges and universities personnel training mode is a more and more long system, degree is higher and higher, far from patients, from the practical application is more and more. This kind of medical education, already can not adapt to the needs of the current education reform, more can not adapt to the needs of the development of medicine in the future. Medical colleges and universities to cultivate both research and to see the doctor, there are both conversion concept and ability and basic knowledge and clinical experience with the combination of talent, the theory from practical mode of medical education must reform completely, and carry out education in general medicine is definitely avoid this kind of current medical talent training and clinical actual demand one of the most effective way of the separation.

\section{THE CONSTRUCtion OF PRACTICE BASE IN GENERAL MEDICINE}

Foreign practical experience proved that community-based teaching compared with the traditional teaching on the basis of the hospital, the former can help medical students improve clinical skills, improve the doctor-patient relationship and the quality of services to meet social needs of the practical training medical talents. According to incomplete statistics, at present our country open an introduction to the general medical courses in medical colleges, most of the elective courses. The lack of standardized community teaching base is due to the current situation of primary care in our country. Present curriculum theory is to teach too much and lack of communities of practice, although some colleges to carry out the community practice, but also does not include all the part of the community itself to carry out the "six" integrated service capabilities [5].

Therefore, approved by the administrative department of public health community health service centers, specification must be approved by teaching practice base construction to become qualified community, to carry out the teaching requirements. Students in the communities of practice base, not only can learn all kinds of service skills, more important is can in accordance with the requirements for community health services and general medical model, to standardize the development of community health service has certain exemplary role [6].

\section{THE TRAINING OF GENERAL PRACTITIONERS NEED THE RELEVANT SUPPORTING POLICIES}

Many countries in the world in general medicine education and guide the graduates to the flows of the community has a corresponding policy support, mainly reflected in the working conditions, job title promotion, continuing education, etc. Our country should perfect the relevant supporting policies, as soon as possible to ensure the general medicine education work scientific, standardized, in-depth and healthy development.
It should focus on teaching contents and at the same time actively absorb the new achievements of medical science and technology. For experimental courses should reduce demonstration and verification experiment, increasing comprehensive and exploratory experiment. Especially in the case of funds and equipment CO., LTD, should optimize the experiment content, make full use of the resources, improve the quality of the experiment, rather than blindly pursue the proportion of experiment and theory. At present, the part of the school of medicine has conducted based on the problems of the reform of the teaching methods. Based on the problem, and teachers as the leading factor, take the student as the main body of team discussion-based teaching in training students' basic clinical skills has obvious advantages compared with traditional methods, can fully mobilize students' learning initiative and enthusiasm, you can also change the old learning methods, so that they take the initiative to acquire knowledge skills, to cultivate and improve the self-learning ability, improve teaching efficiency. Medical institutions shall actively carry out audio-visual teaching, computer-aided teaching, multimedia network teaching, not only can realize sharing of teaching resources, and can create intuitive, vivid and lively teaching environment, enhance students' interest in learning, improve the learning efficiency.

\section{FACTORS AFFECTING THE EFFECT OF THE TRAINING OF GENERAL PRACTITIONER}

In different regions, different countries around the world of job training in general medicine system exists so much difference, the reasons are the following several aspects.

\section{A. The Cost of On-the-job Training}

The cost of on-the-job training in general medicine training costs mainly include administrative expenses, the panel's travel, field test and write a report of time cost, internal academic experts in the process of self-evaluation of the effort and secretarial work, etc., for some countries or institutions, the expenditures of the implementation of the is a big problem.

\section{B. The Independence of the Training Institutions}

If training institutions can't be approved by national or international world, the training of the doctor is unable to work.

\section{The Teachers' Qualification}

Whether level certified professional teachers' qualification and training objective, whether has the academic authority, the relevant certification theory and cognition level, whether to have external political pressure and the ability of intercollegiate conflict of interest will affect the certification smoothly and orderly.

\section{Evaluation System Including Self-evaluation and External Assessment}

Understanding of the concept of accreditation if the school does not reach the designated position, not to be as effective means to promote their own reforms, is bound to be trying to show his advantage at the same time, cover the authenticity of the information provided to the panel could be discounted, may also be selectively arranging on-site visit department, all of these are and runs counter to the concept and purpose of the certification. 


\section{E. Policy Guidance}

This is a very key factor, if can't be open and transparent, no corresponding measures to ensure training effectiveness, training is absolutely won't go too far.

In the United States, job training in general medicine was conducted on a voluntary basis, but all the medical school in the United States to accept the job training in general medicine physicians, because this is the essential condition of the graduates can enter the training program after graduation, and most of the state provisions, only graduated from a certified and qualified medical students can take part in the examination of medical practitioners and get a license. In addition, many state projects and fund will be authenticated as a prerequisite. If schools did not meet the most basic standards, offer certain time limit as a probationary period for rectification, if still not up to standard, then cancel the training qualifications.

\section{F. The Problems Existing in Training of General Practitioner}

Job training in general medicine is to achieve the specification and the ideal state, but there is a problem, major problems can be summarized as:

- Don't form a unified certification standards and certification program is available for reference, so that different parts of the chart.

- The nature and purpose of on job training in general medicine also there is a big mistake in thinking and understanding, leading to the deviation in the process of actual operation.

- On-the-job training in general medicine system establishment and development of more or less by the region economic factors, education experts and helpless.

- Without assessment results cannot play their efficacy and certification is useless.

- It is lack of authority to judge the qualification and level of the training teachers.
To the operation of the concept of job training in general medicine and cognitive deficiency is relatively good solve, as long as how to carry out the relevant training and seminars to communicate can achieve a goal. The most troublesome and economic factors, it has been verified by practice in many areas.

\section{SUMMARY}

To this end, we should take the idea of translational medicine effort to reform the existing medical education content, methods, solve is characterized by general education view of talent training and modern pluralistic orientation contradiction of student employment. Teaching reform is the key to improve the quality of personnel training. First of all, medical colleges should be emerging disciplines, the edge discipline, interdisciplinary teaching, introduced in a timely manner, to increase medicine, community medicine, emergency medicine, public health management, the content of the social disciplines such as integration.

\section{REFERENCES}

[1] Jonathan Betz Brown, Myde Boles, John P Mullooly, et. Effect of Clinic Patient Assessment. Patient Education and Counseling. 2005

[2] Medical Council of Canada. Objective of the Consideration of the Legal Ethical and Organization Aspects of the Practice of Medicine. 1999

[3] Aspergren K. Teaching and learning communication skills in medicine: a review with quality grading or articles. Medical Teacher.

[4] Levinson W. etc. Physician-patient communication: The relationship with malpractice claims among primary care physicians and surgeons. Journal of the American of Medical Association.

[5] Rees M Shepherd. The Acceptability of 360-Degree Judgment as a Method of Assessing Undergraduate Medical Students' Personal and Professional Behaviors. Medical Education. 2005

[6] Medical Council of Canada. Objective of the Consideration of the Legal Ethical and Organization Aspects of the Practice of Medicine. 1999

[7] Timothy J Gallagen, Paul J.Harturg, Stanford W Gregory. Assessment of a measure of relation communication for doctor-patient interactions. Patient Education and Counseling. 2001 